\title{
ESTRESSORES E COPING VIVENCIADOS POR ENFERMEIROS EM UM SERVIÇO DE ATENDIMENTO PRÉ-HOSPITALAR*
}

Eniva Miladi Fernandes Stumm ${ }^{1}$, Cínthia Cristina Oliveski ${ }^{2}$, Carlice Franciane Lima da Costa ${ }^{3}$, Rosane Maria Kirchner ${ }^{4}$, Luiz Anildo Anacleto da Silva ${ }^{5}$

RESUMO: Pesquisa realizada em um Serviço Pré-Hospitalar (SAMU) de Porto Alegre, em 2007. Objetivos: identificar estressores vivenciados por enfermeiros que atuam no SAMU, identificar estratégias de enfrentamento utilizadas para lidar com o estresse no ambiente de trabalho e as repercussões na assistência aos usuários. Participaram 15 enfermeiros e os dados foram coletados mediante o "Inventário de Estresse em Enfermeiros" e analisados com o SPSS-7.5 e estatística descritiva. Estressores: esforço físico, falta de material e pessoal, salário, conflitos entre eles e médicos, competitividade, desgaste emocional, atividades administrativas, responsabilidade pela qualidade dos serviços prestados, política institucional, restrição da autonomia profissional e de espaço para discutir sentimentos. Quanto a interferência dos estressores na assistência, destacam-se falta de treinamento/qualificação e materiais. Os resultados podem significar subsídios para ampliar a qualidade de vida, com repercussões no desempenho, na saúde e na qualidade da assistência.

PALAVRAS-CHAVE: Estresse; Enfermeiros; Assistência pré-hospitalar.

\section{STRESSORS AND COPING EXPERIENCED BY NURSES IN APRE-HOSPITAL ADMISSION CARE DELIVERY}

ABSTRACT: Research study carried out in a pre-hospital admission care delivery (SAMU in Portuguese) in the city of Porto Alegre/Brazil, in 2007. Objectives: to identify stressors experienced by nurses working at SAMU, to identify coping strategies to deal with stress in the work environment and its repercussions in users' care delivery. Fifteen (15) nurses participated in the study and data were collected by the "Nurses' Stress Inventory" and analyzed with SPSS-7.5 and descriptive statistics. Stressors: physical effort, shortage of supplies and personnel, wages, conflicts between them and physicians, competition, emotional stress, administrative tasks, responsibility for the quality of the rendered services, institutional policy, constraint of professional autonomy as well as space to discuss feelings. As for the interference of stressors in care delivery, it is pointed out lack of training/qualification and supplies. Results can mean tools to improve quality of life with repercussions in the performance, in health and in the quality of care delivery.

KEYWORDS: Stress; Nurses; Pre-hospital admission care delivery.

\section{FACTORES DE ESTRÉS Y COPING VIVIDOS POR ENFERMEROS EN SERVICIOS DE ATENCIÓN PRE-HOSPITALARIA}

RESUMEN: La investigación se realizó en un servicio de asistencia en el pre-hospital (SAMU) de Porto Alegre, en 2007. Los objetivos fueron identificar los factores de estrés vividos por enfermeros que actúan en referido local; identificar estrategias de afrontamiento en la atmósfera de trabajo y las repercusiones en la asistencia a los usuarios. Participaron de la investigación quince enfermeros, y los datos fueran recogidos por el uso de "el Inventario de Tensión en Enfermeros" que fueron analizados con SPSS-7.5 y por estadísticas descriptivas. Elementos de estrés: el esfuerzo físico, falta de material y personal, sueldo, conflictos entre enfermeros y médicos, desgaste emocional, competitividad, actividades administrativas, responsabilidad para la cualidad en la prestación de servicios, política institucional, restricción de la autonomía profesional y de espacio para discutir los sentimientos. Cuanto a la interferencia de los elementos de estrés en la asistencia, se destacan falta de entrenar y de cualificación, materiales y de materiales. Los resultados pueden fornecer subsidios para ampliar la cualidad de vida, con las repercusiones en la acción, en la salud y en la cualidad de la asistencia.

PALABRAS CLAVE: Estrés; Enfermería; Atención pre-hospitalaria.

\footnotetext{
*Artigo a partir do Trabalho de Conclusão do Curso de Pós-Graduação Lato-Sensu em Urgência, Emergência e Trauma. Universidade Regional do Noroeste do Estado do Rio Grande do Sul-UNIJUÍ. Defendido em 19/09/2007.

${ }^{1}$ Enfermeira. Mestre em Administração-Recursos Humanos-UFRGS. Docente da UNIJUÍ. Orientadora do TCC.

${ }^{2}$ Enfermeira. Especialista em Urgência, Emergência e Trauma pela UNIJUÍ. Pós-graduanda em Cardiologia pelo Centro Educacional São Camilo. Atua no Serviço de Controle de Infecção Hospitalar do Hospital de Caridade de Ijuí (HCI).

${ }^{3}$ Enfermeira. Especialista em Urgência, Emergência e Trauma pela UNIJUÍ. Atua na Unidade de Internação Obstétrica do Hospital de Clínicas de Porto Alegre (HCPA).

${ }^{4}$ Doutora em Engenharia Elétrica - Métodos de Apoio à Decisão. Docente da UFSM-UNIPAMPAS, São Gabriel.

${ }^{5}$ Enfermeiro. Doutor em Enfermagem pela Universidade Federal de Santa Catarina-UFSC. Docente da UNIJUÍ.
}

Autor correspondente

Eniva Miladi Fernandes Stumm

Rua 20 de setembro, 902 - 98700.000 - Ijuí - RS

Recebido: 22/01/08

Email:eniva@unijui.edu.br

Aprovado: 24/01/08 


\section{INTRODUÇÃO}

O trabalho nos serviços de urgência e emergência incluem a luta diária contra a morte, exigindo esforços e competências da equipe para que a vida vença. Neste ambiente, tudo deve acontecer harmoniosamente, tanto o processo de trabalho integrado da equipe, quanto a existência de materiais/equipamentos adequados, visando segurança e bem-estar do paciente. Quanto maior for a incerteza se determinado evento significativo vai ocorrer ou não, maior a capacidade de gerar sentimento de ameaça aos profissionais que atuam nos referidos serviços ${ }^{(1)}$.

No ambiente pré-hospitalar não se consegue prever os acontecimentos, o que aumenta a necessidade da tomada de decisão rápida e eficaz. Em se tratando de eventos traumáticos, estes assumiram proporções endêmicas, sendo responsáveis por elevados coeficientes de mortalidade no mundo e com repercussões sérias na sociedade como um todo.

Considerando-se a complexidade que o Atendimento Pré-Hospitalar (APH) requer, destacase a existência de estressores nos profissionais que ali atuam, daí a importância do cuidado prestado pelo enfermeiro ser ampliado para que congregue, também, o auto-cuidado deste profissional, o cuidador. Entendese que o atendimento em urgência e emergência é gerador de estresse e de angústia, considerando a gravidade dos pacientes, os procedimentos complexos e, muitas vezes, a morte ${ }^{(2)}$.

Alguns estudos têm mostrado que altos níveis de estresse ocupacional têm efeito negativo sobre o cuidado de pacientes e pode levar à deterioração na qualidade da assistência ${ }^{(3)}$. A relevância deste estudo centra-se em contribuir com subsídios para ampliar a qualidade de vida de profissionais que atuam em APH, pois identificando os estressores, os mesmos podem se constituir em indicadores de gestão, favorecendo a viabilização de ações para minimizar, reduzir e/ou elencar mecanismos de enfrentamento mais adequados para lidar com o estresse no ambiente de trabalho. Essa forma de gerenciamento do estresse ocupacional pode igualmente repercutir em melhora do desempenho do trabalhador, com preservação de sua saúde e ampliação da qualidade da assistência.

Buscou-se com esta pesquisa: identificar estressores vivenciados por enfermeiros que atuam no SAMU, identificar estratégias de enfrentamento utilizadas para lidar com o estresse no ambiente de trabalho e as repercussões na assistência aos usuários.

\section{REFERENCIAL TEÓRICO}

O desenvolvimento do APH no Brasil teve início no Rio de Janeiro, na década de 80 , a partir da percepção de que os acidentes e violências se configuravam em um problema de saúde pública de grande magnitude, com impacto na morbidade e mortalidade da população. De acordo com a Portaria $n^{0}$ 2048/GM que dispõe acerca do Regulamento Técnico dos Serviços de Urgência e Emergência, o atendimento pré-hospitalar é aquele que

procura chegar precocemente à vítima, após ter ocorrido um agravo à sua saúde (de natureza clínica, cirúrgica, traumática, inclusive as psiquiátricas), que possa levar a sofrimento, seqüelas ou mesmo à morte, sendo necessário, portanto, prestar-lhe atendimento e/ou transporte adequado a um serviço de saúde $[. . .]^{(4: 22)}$.

Os princípios básicos que norteiam as ações do APH móvel, de acordo com a Portaria n ${ }^{\circ}$ 2048/ GM são: intervenção no local da ocorrência deve ser rápida, segura, eficaz e com meios adequados; a responsabilidade de cada profissional e as interrelações com os demais devem ser estabelecidas claramente; a qualidade da assistência prestada está diretamente relacionada com o nível de competência dos profissionais e o trabalho em equipe ${ }^{(4)}$.

Situações de urgência e emergência compreendem a atuação conjunta de diferentes profissionais, envoltos pelas exigências do ambiente e do processo de trabalho, lembrando que "os profissionais da saúde têm como objeto de trabalho o bem-estar e a vida de pacientes, estando, portanto, vulneráveis ao estresse"(5:18).

Determinadas situações em que o estado de saúde do usuário encontra-se gravemente comprometido, a equipe de APH realiza o atendimento no próprio local do agravo. Assim, cada situação é única, com variáveis distintas, porém, todas merecedoras de atenção e ações da equipe direcionadas à manutenção da vida, de forma eficiente e eficaz. Inúmeras situações podem dificultar a dinâmica do atendimento em ambiente pré-hospitalar, exigindo da equipe, além de conhecimento científico, habilidades, capacidade de improviso e preparo físico, permanecendo, muitas vezes, em atendimento no local da ocorrência, o tempo necessário para a estabilização inicial da vítima e, posteriormente, transportá-la a um hospital de referência.

A expectativa de envio da equipe para

Cogitare Enferm 2008 Jan/Mar; 13(1):33-43 
atendimentos emergenciais e a possibilidade de mudanças súbitas no estado geral da vítima atendida, podem se constituir estressores, tanto para os profissionais responsáveis pelo atendimento quanto para pacientes e familiares. O deslocamento da ambulância, o tráfego nas vias públicas, os cenários encontrados, o próprio atendimento em si e a família requerem da equipe posturas equilibradas, comportamentos éticos e, a partir disso, organização e eficácia na tomada de decisões para uma assistência adequada e qualificada.

Os profissionais de emergência são submetidos a estressores como sobrecarga de trabalho mental, psíquica e física, além da pressão para tomada de decisões rápidas, fundamentais no atendimento de emergência ${ }^{(6)}$. Estressor é uma situação ou experiência que gera sentimentos de tensão, ansiedade, medo ou ameaça e que pode ter origem interna ou externa ${ }^{(7)}$. Assim, o estresse é um fenômeno complexo e dinâmico, merecedor de atenção dos profissionais da saúde.

Os danos decorrentes do estresse dependem da vulnerabilidade de cada ser humano, personalidade, cultura, valores, dentre outros.

A personalidade das pessoas e a maneira de encarar a vida influencia nas questões do estresse. A mesma situação que para alguns representa uma oportunidade, para outros pode significar uma ameaça ${ }^{(8: 21)}$.

Cada pessoa tende a desenvolver um padrão de comportamento característico do estresse o que caracteriza que o organismo está em desequilíbrio.

Esta situação de desequilíbrio, persistindo, gera a doença ou somatiza no corpo através da preocupação ou do sentimento descontrolado de tristeza, melancolia, perda de algo, ou outra situação que gere um descontrole emocional ou psicológico ${ }^{(9: 2)}$.

Por mais que a subjetividade e a percepção sejam pioneiras no desencadeamento de estresse, as condições de trabalho exercem influência significativa para seu agravo. O estresse ocupacional pode ser entendido como um processo de relação entre trabalho-saúde-doença. Algumas ocupações se caracterizam como mais estressantes que outras, porém o fator determinante é influenciado pela subjetividade individual.

São diversificados os estressores relativos à enfermagem, porém os mais freqüentes são: laborais, sociais e profissionais ${ }^{(10)}$. Os estressores laborais acontecem no ambiente de trabalho, podendo ser desencadeados por quantidade de trabalho excessiva, gerando insatisfação. Outros estressores decorrem da permanência por longo período no trabalho (noite), conflitos trabalho/lar, violência, insegurança; os estressores sociais remetem aos afazeres no lar, assédio sexual, racismo, cuidado com filhos, discriminação pela opção sexual, alvo de fofocas/ brincadeiras no ambiente de trabalho; os estressores profissionais, à organização do Serviço de Enfermagem, estrutura administrativa, contato com sofrimento e morte, riscos de acidentes e contaminação, exposição à visualização, sons e odores desagradáveis e a produtos no ambiente hospitalar.

Considera-se importante que o enfermeiro em APH reconheça os estressores do seu ambiente de trabalho, bem como as repercussões no processo saúde-doença, que os analise de forma objetiva, com uma visão crítica, em busca de soluções para amenizálos, prevenindo danos à sua saúde e garantindo a qualidade da assistência prestada aos usuários.

Neste sentido, o termo coping, traduzido para a língua portuguesa, corresponde às expressões: "formas de lidar com" ou "estratégias de confronto". Enfrentamento ou coping é o que a pessoa realmente pensa e sente, e o que faria em determinadas situações. É uma estratégia que o indivíduo utiliza, não necessariamente consciente, para saber o maior número de informações sobre os acontecimentos e condições psíquicas para proceder de forma a diminuir as respostas de estresse e manter o equilíbrio orgânico ${ }^{(11)}$. Este processo não é estático, pode modificar-se conforme avaliação e reavaliação da situação estressora.

Pensar em enfrentamento implica em criar condições, possibilidades para que as situações com as quais o trabalhador se defronta, acarretem o menor desgaste à sua saúde, à de seus colegas de trabalho e à de usuários. Esses aspectos influenciam na qualidade do atendimento e implicam em trabalhar a partir dos aspectos resilientes, que permitem não apenas enfrentar e sobrepor-se, mas se fortalecer ou se transformar por experiências de diversidade, saudáveis, em relação direta com a capacidade de transformação das práticas ${ }^{(12)}$.

\section{METODOLOGIA}

A pesquisa caracteriza-se como quantitativa, descritiva, exploratória, realizada no Serviço de Assistência Médica de Urgência (SAMU), em Porto Alegre/RS, no mês de julho de 2007. Porto Alegre é a capital do Rio Grande do Sul, maior região 
metropolitana do sul do país, com cerca de 4,1 milhões de pessoas, em julho de 2007.

O SAMU foi instalado em 1995, regulamentado pela Portaria do Ministério da Saúde $\mathrm{n}^{0}$ 2.048. Atualmente conta com uma equipe de 175 profissionais, incluindo médicos, enfermeiros, técnicos em enfermagem e coordenadores e, atende em média, 106 usuários por dia.

Para a solicitação deste serviço, a comunidade pode entrar em contato telefônico gratuito pelo número 192, atendimento 24 horas. A telefonista acolhe a solicitação e registra os dados. Após, a ligação é transferida ao médico regulador, que define o tipo de atendimento/ orientação (Ambulância de Suporte Básico ou Avançado - Unidade de Terapia Intensiva Móvel). Em situações não caracterizadas como risco iminente de vida, o médico orienta outras medidas a serem efetuadas pelo solicitante.

Foram convidados a participar desta pesquisa os 15 enfermeiros que atuam no SAMU e, destes, somente um não entregou os instrumentos preenchidos, totalizando 14 profissinais que, voluntariamente, aceitaram participar. Para a coleta de dados foi utilizado o "Inventário de Estresse em Enfermeiros" (IEE) ${ }^{(13)}$, composto por 44 perguntas fechadas, com grau de intensidade/freqüência para a resposta, acrescido de duas questões abertas, uma referente as repercussões do estresse na assistência e outra ao coping. Também foi utilizado um questionário com dados sociodemográficos e referentes a utilização do tempo fora do trabalho.

A coleta dos dados foi realizada após aprovação da Direção do SAMU. Os enfermeiros, após aceitarem participar da pesquisa, foram agendados horários, conforme disponibilidade e preferência deles. Realizada breve explanação sobre a mesma, destacando objetivos, garantindo segurança quanto à preservação da identidade dos mesmos e orientações em relação à devolução dos respectivos instrumentos, devidamente preenchidos.

Atendendo os aspectos éticos da Resolução 196/ 96 do Conselho Nacional de Saúde ${ }^{(14)}$, os enfermeiros foram convidados a assinar um Termo de Consentimento Livre e Esclarecido, em duas vias, ficando uma em poder deles e outra dos pesquisadores. Foi garantido aos mesmos que não correriam risco algum, nem teriam custos e/ou benefícios monetários ao integrarem-se à população pesquisada e que poderiam desistir da mesma a qualquer momento, se desejassem.

Os dados foram analisados com o software estatístico SPSS, estatística descritiva e Teste Exato de Fisher.

\section{ANÁLISE DOS DADOS}

A maioria dos enfermeiros (85,7\%) é do sexo feminino. Embora as mulheres sejam mais acometidas do que os homens, sabem lidar melhor com o estresse e apresentam menos doenças dele decorrentes, pois conseguem verbalizar mais facilmente sentimentos e problemas vivenciados no dia-a-dia ${ }^{(15)}$.

Dos enfermeiros que integram a pesquisa, $61,5 \%$ são especialistas, (23,4\%) graduados e (15,4\%) mestres, o que demonstra a valorização do aperfeiçoamento profissional para atuar em emergência. A qualificação é primordial para o sucesso e desenvolvimento dos trabalhadores, bem como das organizações em que atuam ${ }^{(16)}$.

Mais da metade (57,1\%) são casados, 28,6\% solteiros e 14,3\% são separados. Sujeitos casados ou que vivenciam união estável são menos propensos à Síndrome de Burnout. A autora refere não só à importância de um relacionamento, mas a qualidade deste como fator de influência para o surgimento do Burnout ${ }^{(17)}$.

Grande parte dos enfermeiros $(71,4 \%)$ possui idade de 40 a 50 anos, (28,6\%) de 20 a 40 anos. Os jovens, recém formados, precisam aprender a lidar com as demandas do trabalho e, por esta razão, podem apresentar maiores níveis de estresse, devido à necessidade de desenvolver autonomia e responsabilidade ${ }^{(18)}$.

A pesquisa revela que metade dos profissionais (50\%) atua como enfermeiro de 20 a 25 anos, sendo 10 anos o menor tempo. Em relação à atuação no SAMU, (28,6\%) deles atuam de 1 a 3 anos e, em percentuais idênticos, de 5 a 7 anos e de 7 a 9 anos. Quanto maior o tempo de serviço dos profissionais da equipe de enfermagem em centro cirúrgico, maior o nível de estresse, existindo, portanto, uma correlação entre estresse e tempo de atuação na área ${ }^{(5)}$.

A seguir, são apresentados os principais resultados obtidos com a utilização do IEE. O mesmo propõe seis categorias para os estressores laborais: fatores intrínsecos para o trabalho, papéis estressores, relações no trabalho, desenvolvimento na carreira, estrutura e cultura organizacional e interface trabalho-casa. Desta forma, o estresse ocupacional é compreendido por meio da identificação de estressores vivenciados no trabalho.

Cogitare Enferm 2008 Jan/Mar; 13(1):33-43 
Fatores intrínsecos ao trabalho correspondem aos recursos inadequados e sobrecarga de trabalho; relações no trabalho significam relações interpessoais e atendimento ao paciente; papéis estressores relacionamse a carga emocional; estrutura organizacional remetese as cobranças e poder de decisão ${ }^{(7)}$.

Tabela 1- Freqüência com que os enfermeiros sentem cada uma das ações relacionadas aos fatores de estresse intrínsecos ao trabalho - IEE. Porto Alegre, 2007

\begin{tabular}{|c|c|c|c|c|c|}
\hline Afirmações & $\begin{array}{l}\text { Nunca } \\
\mathrm{n}(\%)\end{array}$ & $\begin{array}{c}\text { Raramente } \\
\mathrm{n}(\%)\end{array}$ & $\begin{array}{l}\text { Algumas vezes } \\
\mathrm{n}(\%)\end{array}$ & $\begin{array}{c}\text { Muitas vezes } \\
\mathrm{n}(\%)\end{array}$ & $\begin{array}{c}\text { Sempre } \\
\mathrm{n}(\%)\end{array}$ \\
\hline Fazer esforço físico para cumprir o trabalho & $1(7,1)$ & $5(35,7)$ & $4(28,6)$ & $2(14,3)$ & $2(14,3)$ \\
\hline $\begin{array}{l}\text { Desenvolver atividades além da minha função } \\
\text { ocupacional }\end{array}$ & $3(21,4)$ & $6(42,9)$ & $5(35,7)$ & - & - \\
\hline Cumprir na prática uma carga horária maior & $2(14,3)$ & $5(35,7)$ & $5(35,7)$ & $2(14,3)$ & - \\
\hline Levar serviço para fazer em casa & $4(28,6)$ & $6(42,9)$ & $3(21,4)$ & - & $1(7,1)$ \\
\hline Falta de material necessário ao trabalho & - & $4(28,6)$ & $6(42,9)$ & $4(28,6)$ & - \\
\hline Falta de recursos humanos & - & $2(14,3)$ & $7(50,0)$ & $5(35,7)$ & - \\
\hline Trabalhar em instalações físicas inadequadas & - & $4(28,6)$ & $6(42,9)$ & $4(28,6)$ & - \\
\hline Trabalhar em horário noturno* & $2(14,3)$ & $7(50,0)$ & $1(7,1)$ & $1(7,1)$ & $2(14,3)$ \\
\hline Trabalhar em ambiente insalubre & $2(14,3)$ & $3(21,4)$ & $6(42,9)$ & $2(14,3)$ & 1 \\
\hline Executar procedimentos rápidos & $2(14,3)$ & $8(57,1)$ & $3(21,4)$ & $1(7,1)$ & - \\
\hline Receber este salário & $1(7,1)$ & $6(42,9)$ & $2(14,3)$ & $3(21,4)$ & $2(14,3)$ \\
\hline
\end{tabular}

* um enfermeiro não respondeu

Para 28,6\% dos enfermeiros, correspondente à soma das freqüências muitas vezes ou sempre, sentem o esforço físico para atuar na unidade como um estressor. Outros dados que chamam atenção dizem respeito ao trabalho em instalações físicas inadequadas (28,6\%), falta de materiais (28,6\%) e de profissionais (35,7\%) que, igualmente, são sentidos por eles, muitas vezes, como estressores. $\mathrm{O}$ ambiente físico interfere na saúde física do trabalhador e o desgaste físico e emocional pode ter um impacto fatal e causar grave deterioração do desempenho no trabalho ${ }^{(5,19)}$.

Outro resultado que chama atenção é que metade dos enfermeiros, somando as freqüências algumas vezes ou muitas vezes, sente que cumprir uma carga horária maior não se constitui fator estressor, porém, em percentual idêntico, nunca ou raramente eles sentem o referido fator como estressor. Do ponto de vista da empresa, carga de trabalho significa produtividade e, do indivíduo, tempo é energia. Desta maneira, o excesso de trabalho é a indicação elementar de desequilíbrio entre o indivíduo e seu emprego, na medida em que prejudica a qualidade, desfaz relações com colegas e ocasiona desgaste físico e emocional ${ }^{(19)}$.

As respostas de mais de $60 \%$ dos enfermeiros à afirmação "trabalhar em horário noturno" indicam que não sentem este fator como estressor, porém 21,4\% sente. O trabalho noturno contínuo da enfermagem proporciona déficit de sono, problemas de vigilância, alterações no humor e riscos na qualidade da assistência, efeitos negativos sobre a vida social ou familiar, entre outros. Isso contribui para a diminuição da capacidade de audição, rapidez, precisão e memorização ${ }^{(10)}$.

Em relação à questão salarial, explicitada na Tabela1, para 35,7\% dos enfermeiros, nas freqüências muitas vezes ou sempre é sentido como um estressor. Neste contexto, a atual crise no ambiente de trabalho reduz a capacidade das organizações em remunerar os profissionais de forma adequada ${ }^{(19)}$.

Para mais de $40 \%$ dos enfermeiros, Tabela 2, muitas vezes ou sempre, trabalhar com profissionais despreparados é estressante. Atuar em APH requer elevada exigência em termos de performance, incluindo conhecimento específico, habilidades e destrezas na execução de técnicas, na qual o fator tempo é crucial para a assistência. Estes fatores, se associados a uma equipe com profissionais despreparados para assumir tais funções, pode interferir negativamente na assistência ao paciente. 
Tabela 2- Freqüência com que os enfermeiros sentem cada uma das ações relacionadas aos fatores estressores nas relações no trabalho - IEE, Porto Alegre, 2007

\begin{tabular}{lccccc}
\hline \multicolumn{1}{c}{ Afirmações } & Nunca & Raramente & Algumas vezes & Muitas vezes & Sempre \\
& $\mathrm{n}(\%)$ & $\mathrm{n}(\%)$ & $\mathrm{n}(\%)$ & $\mathrm{n}(\%)$ & $\mathrm{n}(\%)$ \\
\hline Começar em uma função nova & $4(28,6)$ & $3(21,4)$ & $5(35,7)$ & $2(14,3)$ & - \\
Conciliar as questões profissionais com as & $1(7,1)$ & $6(42,9)$ & $5(35,7)$ & $2(14,3)$ & - \\
familiares & & & & & \\
Trabalhar com pessoas despreparadas & $1(7,1)$ & $2(14,3)$ & $5(35,7)$ & $5(35,7)$ & $1(7,1)$ \\
Relacionamento com os colegas enfermeiros & $1(7,1)$ & $4(28,6)$ & $5(35,7)$ & $4(28,6)$ & - \\
Relacionamento com a equipe médica & $3(21,4)$ & $4(28,6)$ & $4((28,6)$ & $2(14,3)$ & $1(7,1)$ \\
Relacionamento com a chefia & $2(14,3)$ & $6(42,9)$ & $4(28,6)$ & $2(14,3)$ & - \\
Trabalhar em equipe & $3(21,4)$ & $7(50,0)$ & $4(28,6)$ & - & - \\
Prestar assistência a pacientes graves & $3(21,4)$ & $8(57,1)$ & $2(14,3)$ & - & $1(7,1)$ \\
Atender familiares de pacientes & $1(7,1)$ & $6(42,9)$ & $5(35,7)$ & $1(7,1)$ & $1(7,1)$ \\
Ensinar o aluno & $7(50,0)$ & $6(42,9)$ & $1(7,1)$ & - & - \\
Atender um número grande de pessoas & $3(21,4)$ & $4(28,6)$ & $6(42,9)$ & - & $1(7,1)$ \\
\hline
\end{tabular}

No que concerne às relações interpessoais entre os enfermeiros, para $28,6 \%$, muitas vezes se constitui um estressor, assim como com a chefia $(14,3 \%)$ e a equipe médica $(14,3 \%)$. As relações interpessoais são importantes no sentido de evitar o adoecimento pelo trabalho, principalmente a Síndrome de Bournout. O conflito é inerente à relação entre pessoas e não deve ser encarado como negativo. Segundo as autoras, muitas situações conflitantes são importantes como sinalizadoras de mudanças, oportunizando repensar e, posteriormente, modificar formas de agir na unidade ${ }^{(20)}$.

Tabela 3 - Freqüência com que os enfermeiros sentem cada uma das ações relacionadas aos papéis estressores da carreira - IEE, Porto Alegre, 2007

\begin{tabular}{lccccc}
\hline \multicolumn{1}{c}{ Afirmações } & Nunca & Raramente & Algumas vezes & Muitas vezes & Sempre \\
& $\mathrm{n}(\%)$ & $\mathrm{n}(\%)$ & $\mathrm{n}(\%)$ & $\mathrm{n}(\%)$ & $\mathrm{n}(\%)$ \\
\hline Fazer um trabalho repetitivo & $1(7,1)$ & $8(57,1)$ & $3(21,4)$ & $2(14,3)$ & - \\
Sentir desgaste emocional com o trabalho & - & $3(21,4)$ & $8(57,1)$ & $3(21,4)$ & - \\
Trabalhar em clima de competitividade & - & $2(14,3)$ & $6(42,9)$ & $4(28,6)$ & $2(14,3)$ \\
Prestar assistência ao paciente & $3(21,4)$ & $10(71,4)$ & $1(7,1)$ & - & - \\
Distanciamento entre a teoria e a prática & $2(14,3)$ & $4(28,6)$ & $7(50,0)$ & $1(7,1)$ & - \\
Desenvolver pesquisa & 4 & $6(42,9)$ & $3(21,4)$ & $1(7,1)$ & $1(7,1)$ \\
$\begin{array}{l}\text { Sentir-se impotente diante das tarefas a serem } \\
\text { realizadas }\end{array}$ & $1(7,1)$ & $6(42,9)$ & $5(35,7)$ & $1(7,1)$ & - \\
$\begin{array}{l}\text { Dedicação exclusiva à profissão } \\
\text { Indefinição do papel do enfermeiro }\end{array}$ & $4(28,6)$ & $7(50,0)$ & $2(14,3)$ & $1(7,1)$ & $1(7,1)$ \\
$\begin{array}{l}\text { Responsabilizar-se pela qualidade de serviço que } \\
\text { a Instituição presta* }\end{array}$ & $1(7,1)$ & $4(28,6)$ & $3(21,4)$ & $5(35,7)$ & - \\
$\begin{array}{l}\text { Impossibilidade de prestar assistência direta ao } \\
\text { paciente* }\end{array}$ & $6(42,9)$ & $3(21,4)$ & $3(21,4)$ & $1(7,1)$ & - \\
\hline
\end{tabular}

* um sujeito não respondeu 
Metade dos enfermeiros pesquisados não sente a assistência aos familiares de pacientes como um estressor, porém os demais, nas freqüências algumas vezes, muitas vezes ou sempre, sim. Afamília se constitui no grupo social mais importante do indivíduo, responsável pelo apoio físico, emocional e social. Assim, sua inserção na assistência ao paciente é importante na medida em que ela pode complementar o cuidado profissional, mediante informações a respeito do paciente.

Na Tabela 3, evidencia-se que o sentimento de desgaste emocional com o trabalho é uma constante para mais da metade dos enfermeiros somente na freqüência algumas vezes e para $21,4 \%$, muitas vezes. Aliando-se este resultado as respostas quanto a trabalhar em clima de competitividade, para mais de $40 \%$, muitas vezes ou sempre é estressante e "responsabilizar-se pela qualidade de serviço que a Instituição presta” para um percentual aproximado, é igualmente sentido muitas vezes como um estressor. Estes resultados merecem atenção do gestor do APH, para desenvolver ações visando melhorar as relações entre profissionais e instituição e reverter este quadro. O excesso de trabalho, co-relacionado com o desgaste emocional, foi o precursor da psicopatologia do contexto laboral, tendo como conseqüência o adoecimento do trabalhador ${ }^{(21)}$.

Dois dados positivos que se destacam na Tabela 3 referem-se ao sentimento de clareza quanto as funções/atribuições do enfermeiro em APH e a assistência ao paciente, pois a maioria dos pesquisados nunca ou raramente sente estes aspectos como estressores. O trabalho ocupa um lugar essencial na vida das pessoas. Se estiver a contento em suas habilidades, ele é uma das formas mais prazerosas, e de satisfação que elas experimentam. Se ocorrer o oposto, o que deveria ser fonte de satisfação pode tornarse fonte inesgotável de sofrimento. Além disso, a fragilidade psíquica gera debilidade, também no corpo físico, já que ambos estão conjugados ${ }^{(22)}$.

Quanto ao sentimento dos enfermeiros sobre o distanciamento entre teoria e prática, para 43,9\% não se constitui fator estressor, mas para os demais, algumas vezes o é. Relacionando este resultado aos dados sociodemográficos, $61,5 \%$ são especialistas, e, mesmo com cursos de especialização, sentem distanciamento entre teoria e prática. Entende-se que as instituições formadoras desses profissionais possuem papel importante no sentido de torná-los agentes de mudança, com o propósito de fornecer estratégias que possibilitem a melhoria da organização, da equipe de enfermagem e principalmente da assistência prestada ao paciente.

Na Tabela 4, quanto aos estressores relacionados à estrutura e cultura organizacional, destaca-se o fato de $42,9 \%$ dos enfermeiros raramente sentirem como estressante ter que resolver situações não previsíveis no ambiente de trabalho e um percentual idêntico, somente algumas vezes o sentem. Importante ressaltar que a imprevisibilidade é intrínseca no atendimento préhospitalar, daí a necessidade do preparo da equipe.

Tabela 4 - Freqüência com que os enfermeiros sentem cada uma das ações relacionadas aos fatores estressores relacionados com a estrutura e cultura organizacional - IEE, Porto Alegre, 2007

\begin{tabular}{|c|c|c|c|c|c|}
\hline Afirmações & $\begin{array}{l}\text { Nunca } \\
\mathrm{n}(\%) \\
\end{array}$ & $\begin{array}{c}\text { Raramente } \\
\mathrm{n}(\%)\end{array}$ & $\begin{array}{c}\text { Algumas } \\
\text { vezes } \\
\mathrm{n}(\%) \\
\end{array}$ & $\begin{array}{c}\text { Muitas } \\
\text { vezes } \\
\mathrm{n}(\%) \\
\end{array}$ & $\mathrm{n}(\%)$ \\
\hline Executar tarefas distintas simultaneamente & $3(21,4)$ & $5(35,7)$ & $6(42,9)$ & - & - \\
\hline Resolver imprevistos que acontecem no local de trabalho & - & $6(42,9)$ & $6(42,9)$ & $2(14,3)$ & - \\
\hline Responder por mais de uma função neste emprego & $5(35,7)$ & $4(28,6)$ & $4(28,6)$ & $1(7,1)$ & - \\
\hline Administrar ou supervisionar o trabalho de outras pessoas & $1(7,1)$ & $2(14,3)$ & $6(42,9)$ & $5(35,7)$ & - \\
\hline Manter-se atualizada & $3(21,4)$ & $6(42,9)$ & $3(21,4)$ & $2(14,3)$ & - \\
\hline $\begin{array}{l}\text { Falta de espaço no trabalho para discutir as experiências, } \\
\text { tanto as positivas como as negativas }\end{array}$ & $2(14,3)$ & $2(14,3)$ & $3(21,4)$ & $5(35,7)$ & $2(14,3)$ \\
\hline Fazer turnos alternados de trabalho & $4(28,6)$ & $6(42,9)$ & $1(7,1)$ & $2(14,3)$ & $1(7,1)$ \\
\hline Ter um prazo curto para cumprir ordens & $1(7,1)$ & $8(57,1)$ & $4(28,6)$ & $1(7,1)$ & - \\
\hline Restrição da autonomia profissional & $3(21,4)$ & $4(28,6)$ & $2(14,3)$ & $4(28,6)$ & $1(7,1)$ \\
\hline Interferência da Política Institucional no trabalho & - & $4(28,6)$ & $6(42,9)$ & $3(21,4)$ & $1(7,1)$ \\
\hline A especialidade em que trabalho & $4(28,6)$ & $7(50,0)$ & $3(21,4)$ & - & - \\
\hline
\end{tabular}


Seguindo pressupostos de autores clássicos da administração, a tomada de decisão é um dos assuntos centrais para a administração em qualquer organização. Para além deste contexto, a tomada de decisão e a resolução de imprevistos se inter-relacionam com a assistência prestada ao paciente. Decidir significa escolher a melhor alternativa à situação, visando alcançar resultados desejados.

Observa-se que a maioria dos enfermeiros (78,6\%), nas freqüências algumas vezes ou muitas vezes, sentem as atividades administrativas, tanto em relação ao trabalho em si, quanto a gestão de pessoas, como estressoras. Atualmente, a prática de administrar vem sendo exercida em instituições de saúde, envolvendo não apenas o administrador, mas pessoas que se relacionam diretamente com esta e que assumem o desafio de planejar, organizar, coordenar e direcionar as atividades e as pessoas. Importante destacar que na medida em que se somam atribuições aos profissionais, pode favorecer a ocorrência do estresse.

Intrínseca à organização está a política institucional que refere-se a um dos muitos estressores em potencial associados ao ambiente de trabalho ${ }^{(23)}$. Esta colocação do autor vem ao encontro das respostas de $71,4 \%$ dos enfermeiros, somando as freqüências algumas vezes, muitas vezes ou sempre, os quais sentem a interferência da política institucional no trabalho como um estressor. Neste sentido, "cabe às empresas criar o espaço, estimular o desenvolvimento e oferecer o suporte e as condições para uma relação de alavancagem mútua das expectativas e necessidades”(24:48).

Na população pesquisada, $71,4 \%$ sente falta de oportunidade para discutir experiências, sentimentos vivenciados no trabalho. O relacionamento interpessoal pode fornecer apoio para o trabalhador enfrentar as situações de desgaste e estresse no seu dia-a-dia profissional. Desta maneira, compartilhar sentimentos e frustrações pode fortalecer o mesmo, na medida em que é possível encontrar no convívio grupal maneiras de identificar reflexões semelhantes às suas.

Para encontrar o equilíbrio, é importante que tanto a empresa quanto os profissionais estejam conscientes dos fatores estressores que partilham. Para tanto, há a necessidade de os mesmos desejarem fazer as adaptações necessárias para um maior controle pessoal. As emoções e a saúde física dependem quase que exclusivamente da interpretação de cada um sobre o mundo exterior. Quanto mais cada um entende as pressões e situações que o influenciam, melhor se adapta às demandas ${ }^{(15)}$.
A seguir, é apresentado o Teste Exato de Fisher, para testar a hipótese de que duas variáveis estão associadas. Foram cruzados dados sociodemográficos com as estatísticas oriundas do uso do IEE, sendo que de todas as variáveis testadas, somente duas apresentaram resultados significativos.

Analisando-se a Figura 1, é possível afirmar que $75 \%$ dos enfermeiros que se dedicam exclusivamente para o SAMU percebem falta de espaço para discutir as experiências vivenciadas no trabalho e os que possuem mais de um vínculo empregatício, apenas 17\% o sentem desta forma. Nesta relação, o teste Exato de Fisher apresentou $\mathrm{p}=0,051$, demonstrando que há uma correlação significativa entre as variáveis.

Os enfermeiros com dedicação exclusiva podem ter maior identificação com o trabalho, preocupação com assuntos relativos ao SAMU, enquanto para os que atuam em dois ou mais locais de trabalho, estas questões podem não ser significativas na medida em que possuem mais atividades a serem desenvolvidas.

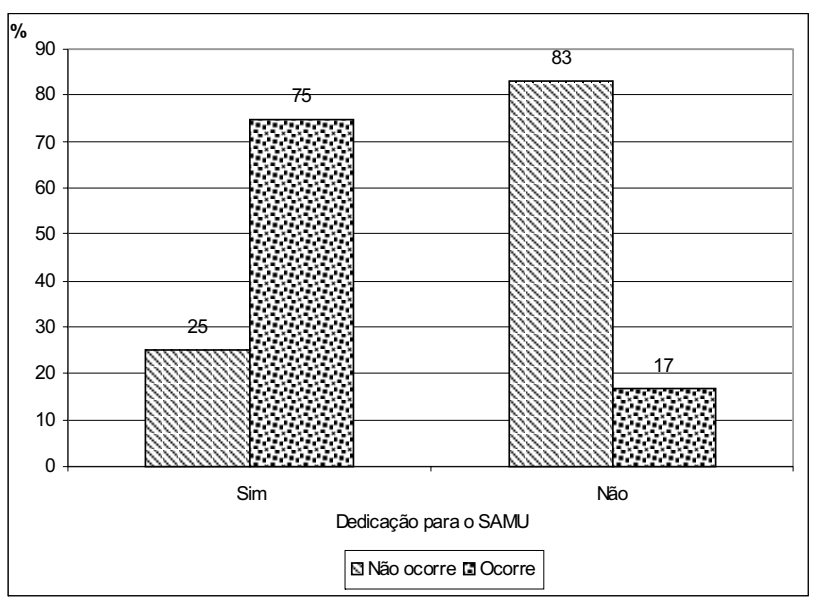

Teste Exato de Fisher com p=0,051

Figura 1 - Dedicação para o SAMU segundo a ocorrência da falta de espaço no trabalho para discutir as experiências, tanto positivas como negativas

A Figura 2 demonstra a relação entre o tempo de profissão com a falta de profissionais. Nesta relação, o teste Exato de Fisher apresentou $p=0,051$, demonstrando, igualmente, correlação significativa entre as variáveis. Observa-se que $67 \%$ dos enfermeiros que atuam de 10 a 20 anos consideram a falta de profissionais como um estressor, enquanto que $29 \%$ que exercem a profissão de 20 a 30 anos percebem a correlação entre estresse e falta de profissionais. Deste modo, verificase que nesta pesquisa, à medida em que aumenta o tempo de exercício da enfermagem, os profissionais 
parecem se acostumar com o número reduzido de membros da equipe.

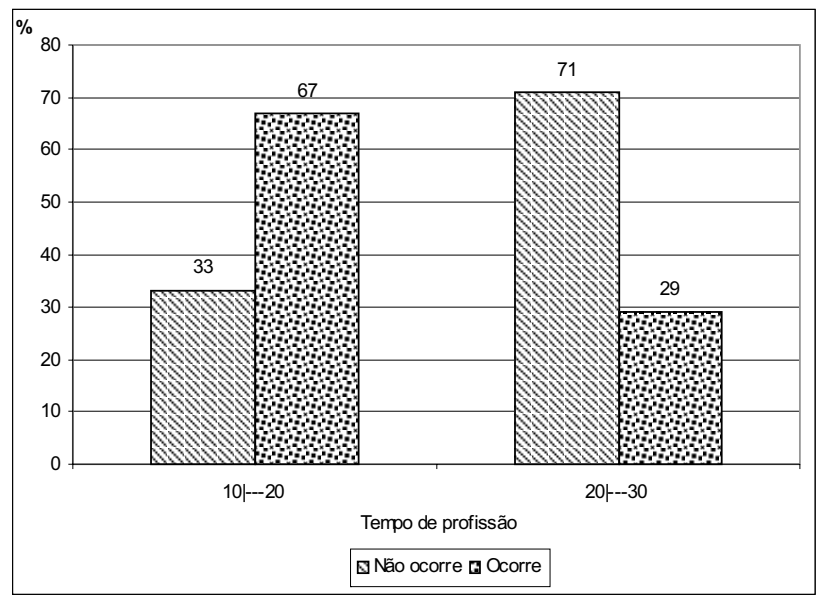

Teste Exato de Fisher com p=0,051

Figura 2 - Tempo de profissão segundo a falta de profissionais

Os enfermeiros foram questionados quanto a possível interferência dos estressores vivenciados na assistência ao paciente. As respostas foram quantificadas e analisando-se os posicionamentos dos pesquisados, os que se destacaram foram: falta de treinamento/qualificação e falta de materiais. Chama atenção o fato de três enfermeiros afirmarem que o atendimento eficiente e humanizado se constitui fator estressor e este mesmo número considera que os estressores não interferem na assistência ao paciente.

As necessidades pessoais do trabalhador de enfermagem e sua ansiedade em relação às circunstâncias com as quais ele se defronta, como por exemplo, a falta de materiais e pessoal, a grande responsabilidade sobre o paciente, o contato com situações de morte, o perigo de acidentar-se no desenvolver de suas atividades, geralmente, prejudicam o atendimento que ele sabe dar e que gostaria de poder dar, podendo causar sofrimento no profissional ${ }^{(2)}$.

Os enfermeiros igualmente foram questionados quanto as estratégias de enfrentamento aos estressores no ambiente de trabalho e as que se destacaram foram: "desligar" do trabalho, realizar atividades físicas, estabelecer diálogo no ambiente de trabalho e estar com a família.

Enfrentamento ou coping é uma estratégia que o indivíduo utiliza, não necessariamente, consciente, para saber o maior número de informações sobre os acontecimentos e condições psíquicas para proceder de forma a diminuir as respostas de estresse e manter o equilíbrio orgânico ${ }^{(11)}$. Esse processo não é estático, podendo modificar-se conforme avaliação e reavaliação da situação estressante.

Associando os estressores que os enfermeiros apontaram como presentes em seu trabalho que, segundo a literatura pesquisa, é gerador de estresse, justifica-se a necessidade de os profissionais elencarem e utilizarem mecanismos de enfrentamento, na tentativa de minimizar e/ou de se adaptar às diferentes situações estressoras. Se o coping for efetivo, o indivíduo obterá a solução do problema ou a diminuição da emoção e o evento estressor poderá ser superado; caso as estratégias forem ineficazes, instalar-se-á a crise e a continuidade do processo de estresse, tornando-se indispensável uma reavalição do estressor.

São formas de enfrentamento ao estresse: técnicas de relaxamento, alimentação adequada, exercício físico regular, repouso, lazer e diversão, sono apropriado às necessidades individuais, métodos psicoterapêuticos, processos que favoreçam o autoconhecimento, estruturação do tempo livre com atividades prazerosas e ativas, avaliação periódica de sua qualidade de vida, reavaliação de seu limite de tolerância e exigência, busca de convivência menos conflituosa com pares e grupos ${ }^{(1)}$.

A forma como se dá o processo de organização do trabalho da enfermagem, muitas vezes, não leva em consideração os problemas do trabalhador, que enfrenta dificuldades fora e dentro do trabalho. Pensase que no momento em que o profissional reconhece os fatores que lhe prejudicam, pode desenvolver habilidades visando evitar e/ou minimizar o estresse, tornando sua vida mais afável, permitindo um desempenho otimizado de suas funções. Importante lembrar que o cuidado é um instrumento de trabalho do enfermeiro e, ao mesmo tempo, pode causar danos à saúde deste cuidador. Então, é essencial que ele aprenda a se cuidar, evitando os danos desta ocupação e proporcionando uma assistência integral ao paciente.

\section{CONSIDERAÇÕES FINAIS}

Nos Serviços de Urgência e Emergência espera-se que tudo aconteça harmoniosamente, com profissionais preparados, materiais e equipamentos adequados, visando segurança e bem-estar do paciente. Devido à complexidade das situações vivenciadas pelos profissionais no referido ambiente, aliadas a subjetividade de cada um, condições do ambiente, relações interpessoais, dentre outros, 
inúmeros são os estressores vivenciados pelos profissionais que neles atuam.

Toda organização de trabalho é um sistema social formado por pessoas com valores, sentimentos, comportamentos, normas e regras organizacionais. $\mathrm{O}$ trabalhador age no sentido de afastar-se daquilo que o faz sofrer e aproximar-se do que lhe traz satisfação. Os enfermeiros pesquisados vivenciam inúmeros estressores e reconhecem a interferência destes no ambiente de trabalho, e para tal, utilizam estratégias de enfrentamento. Porém, é evidente a necessidade de implementação de outras estratégias de enfrentamento, visando minimizar os estressores e melhorar a qualidade de vida destes profissionais. Ao término da pesquisa, pode-se afirmar que o objetivo proposto foi alcançado.

Os resultados desta pesquisa podem servir de subsídios para ampliar a qualidade de vida dos profissionais que atuam em APH. A identificação dos estressores pode se constituir indicadores de gestão, viabilizando ações para minimizar, reduzir e/ou elencar mecanismos de enfrentamento eficazes para lidar com o estresse no trabalho, com repercussões no desempenho, na saúde e na qualidade da assistência. Esta pesquisa pode igualmente contribuir para o aprimoramento da compreensão do estresse em APH, propiciar reflexões e discussões entre profissionais que atuam nesta área e estimular pesquisadores no sentido de utilizar o IEE em populações maiores, podendo-se, inclusive, fazer inferências.

\section{REFERÊNCIAS}

1. França ACL, Rodrigues AL. Stress e trabalho: uma abordagem psicossomática. São Paulo: Atlas; 2002.

2. De Gasperi P, Radünz V. Cuidar de si: essencial para enfermeiros. REME - Rev Min Enferm 2006 Jan/Mar; 10(1):82-7.

3. Menzani G. Stress entre enfermeiros brasileiros que atuam em pronto socorro [dissertação]. São Paulo (SP): Escola de Enfermagem. Universidade de São Paulo; 2006.

4. Ministério da Saúde (BR). Regulamento técnico dos sistemas de urgência e emergência. Brasília, 2004.

5. Caregnato RC. Estresse da equipe multiprofissional na sala de cirurgia: um estudo de caso [dissertação]. Porto Alegre (RS): Escola de Enfermagem. Universidade do Rio Grande do Sul; 2002.

6. Deslandes SF. Violência no cotidiano dos serviços de emergência hospitalar: Representações, práticas, interações e desafios [tese]. Rio de Janeiro (RJ): Escola Nacional de Saúde Pública; 2000.

7. Stacciarini JMR, Tróccol BT. O Estresse na atividade ocupacional do enfermeiro. Rev Latino-Am Enferm. 2001 Mar; 9(2):17-25.

8. Stumm EMF. O estresse de equipes de enfermagem que atuam em unidades de centro cirúrgico nos hospitais da cidade de Ijuí [dissertação]. Porto Alegre (RS): Universidade Federal do Rio Grande do Sul; 2000.

9. Santini AM, Costenaro RGS, Medeiros HMF, Zaberlan C. Estresse: vivência profissional de enfermeiras que atuam em utineonatal. Cogitare Enferm. 2005 Set/ Dez;10(3):14-22.

10. Bulhões I. Riscos do trabalho de enfermagem. Rio de Janeiro: Copyright; 1994.

11. Medeiros VCC, Peniche ACG. A influência da ansiedade nas estratégias de enfrentamento utilizadas no período pré-operatório. Rev Escol Enferm. 2006; 40(01): 86-92.

12. Lancman S. Saúde, trabalho e terapia ocupacional. São Paulo: Roca; 2004

13. Stacciarini JMR, Trócolli BT. Instrumento para mensurar o estresse ocupacional: inventário de estresse em enfermeiros (IEE). Rev Latino-Am Enferm. 2000 Dez; 8(6):40-9.

14. Brasil. Ministério da Saúde. Conselho Nacional da Saúde. Diretrizes e normas regulamentadoras da pesquisa envolvendo os seres humanos: Resolução 196/96. Brasília, 1996.

15. Rossi A M. Estressado, eu? Porto Alegre: RBS produções; 2004.

16. Resende E, Takershina ML. RH em tempo real: conceitos e ferramentas modernas para gestão de recursos humanos. Rio de janeiro: Quality Mark; 2000.

17. Pereira MER, Bueno SMV. Lazer - um caminho para aliviar as tensões no ambiente de trabalho em UTI: uma concepção da equipe de enfermagem. Rev Latino-Am Enferm. 1997 Out; 5(4):75-83.

18. Carlotto MS, Nakamura AP, Câmara SG. Síndrome de Burnout em estudantes universitários da área da saúde. Psico [periódico na internet]. 2006[acesso em 2007 Set 16]37(1):57-62. Disponível em: http://www.pucrs.br/ psico/revistapsico.

Cogitare Enferm 2008 Jan/Mar; 13(1):33-43 
19. Maslach C, Leiter MP. Trabalho: fonte de prazer ou desgaste? Guia para vencer o estresse na empresa. Campinas, SP: Papirus; 1999.

20. Stumm EMF, Maçalai R, Kirchner RM. Dificuldades enfrentadas por enfermeiros de um Centro Cirúrgico. Texto Contexto Enferm. 2006 Jul/Set;15(3):464-71

21. Dejours C, Abdoucheli E, Jayet C. Psicodinâmica do Trabalho. São Paulo: Atlas; 1994.

22. França ACL. Qualidade de vida no trabalho. São Paulo: Atlas; 2003.

23. Ferris GR, Brouer R, Laird MD, Hochwarter W. As conseqüências das percepções da política organizacional como estressor no local de trabalho. In: Rossi AM, Perrewé P, Sauter S. Stress e qualidade de vida no trabalho. São Paulo: Atlas; 2005. p156-63.

24. Dutra JS. Gestão de pessoas: modelo, processos, tendências e perspectivas. São Paulo: Atlas; 2006. 